\section{Booktube: um gênero discursivo advindo das Tecnologias Digitais da Informação e Comunicação}

Booktube: a speech genre derived from

Digital Information and Communication Technologies

Dayana Junqueira AYRES (UESB) dayana.ayres@hotmail.com

Márcia Helena de Melo PEREIRA (UESB) marciahelenad@yahoo.com.br Ana Claudia Oliveira AZEVEDO (UESB) 98anaclaudia@gmail.com

Recebido em: 18 de jan. de 2021. Aceito em: 30 de ago. de 2021.
AYRES, Dayana Junqueira; PEREIRA, Márcia Helena de Melo; AZEVEDO, Ana Claudia Oliveira. Booktube: um gênero discursivo advindo das Tecnologias Digitais da Informação e Comunicação Entrepalavras, Fortaleza, v. 11, n. 3, e2210, p. 386-412, set.-dez./2021. DOI: 10.22168/2237-6321-32210.

Resumo: O objetivo deste trabalho é investigar e caracterizar um gênero advindo das Tecnologias Digitais da Informação e Comunicação (TDICs): o booktube. A classificação do booktube como gênero do discurso é feita com base na organização triádica proposta por Bakhtin (2011), segundo a qual os gêneros são compostos por conteúdo temático, estilo e construção composicional. Para o corpus, foram selecionados três vídeos postados por diferentes canais de booktubers na comunidade YouTube. A análise dos dados mostrou que 0 booktube é um gênero do discurso que apresenta uma relativa estabilidade em seu conteúdo temático, construção composicional e estilo do gênero; porém, é bastante propício à manifestação do estilo individual de quem o produz.

Palavras-chave: Gêneros discursivos. Tecnologias Digitais. Booktube. 
Abstract: The aim of this work is to investigate and characterize a genre derived from Digital Information and Communication Technologies (DICT): the booktube. The classification of booktube as a speech genre is based on the threefold organization proposed by Bakhtin (2011), whereby speech genres are composed by thematic content, style, and compositional structure. For the corpus, three samples of the genre, posted by different booktube channels in the YouTube community, were selected. The data analysis showed that booktube is a speech genre which presents a relative stability in its thematic content, compositional structure, and genre style; however, it is very propitious to the manifestation of the individual style of its producer.

Keywords: Speech genres. Digital Technologies. Booktube.

\section{Introdução}

O teórico russo Mikhail Bakhtin (2011) postula que todo uso da língua - oralmente ou de forma escrita - ocorre em um dado gênero do discurso. Para o Círculo de Bakhtin, os gêneros do discurso são tipos relativamente estáveis de enunciados, que são produzidos e circulam em determinado campo da comunicação humana, com suas particularidades históricas, sociais e culturais.

As Tecnologias Digitais da Informação e Comunicação (TDICs) fizeram com que a cultura digital passasse a ocupar grande parte da nossa vida, já que as mídias digitais e a internet habitam, hoje, a palma de nossas mãos, por meio do uso de aparelhos móveis como smartphones. Desse modo, a partir da popularização dessas tecnologias, novas formas de comunicação surgiram, tornando necessários estudos a respeito de possíveis gêneros emergentes. A relevância dessas pesquisas é ratificada pela Base Nacional Comum Curricular (BRASIL, 2018), documento de caráter normativo que define as aprendizagens essenciais que todos os alunos devem desenvolver ao longo das etapas e modalidades da educação básica e ressalta a necessidade de abordagem das TDICs e da Cultura Digital no ambiente escolar.

Dentre as novas formas de comunicação originadas pelas TDICs, ressaltamos o booktube, objeto desta investigação ${ }^{1}$. O termo booktube é de origem inglesa e representa a junção dos vocábulos book (livro) e tube, sufixo de YouTube (plataforma de compartilhamento de vídeos). Portanto, trata-se de vídeos produzidos por pessoas denominadas booktubers, interessadas em falar sobre suas leituras literárias, descrevendo-as e indicando-as ou não aos seus espectadores no ambiente YouTube (SILVA, 2019).

\footnotetext{
${ }^{1}$ Este trabalho é fruto de discussões realizadas na tese de doutorado intitulada O gênero booktube em sala de aula: tecnologia como ferramenta para a educação, que está em construção no Programa de Pós-Graduação em Linguística (PPGLin) da Universidade Estadual do Sudoeste da Bahia (UESB).
} 
V. $11(3)$

$386-412$

set-dez

2021

Considerando a necessidade de compreensão e sistematização dessas novas práticas de linguagem, o objetivo deste trabalho é classificar o booktube como gênero do discurso, com base, principalmente, na teoria enunciativo-discursiva de Bakhtin (2011), segundo a qual os gêneros do discurso, por meio dos quais nos comunicamos, são constituídos por conteúdo temático, estilo e construção composicional. Ressaltamos que não pretendemos esgotar as discussões sobre o tema, não só pela amplitude de questões a ele inerentes, mas também pela delimitação da amostra analisada.

Embasamo-nos, também, nas discussões de I. Machado (2005), Faraco (2009), Sobral (2009), Ribeiro (2010), Rojo (2013) e Rojo e Barbosa (2015) acerca das características dos gêneros do discurso, com base na teoria bakhtiniana. Além disso, a fim de abranger a multimodalidade, adotamos as proposições de Dionisio (2011) e Rojo e Barbosa (2015), bem como de Rojo (2013), que amplia a teoria bakhtiniana aos gêneros das novas mídias. A partir desses pressupostos teóricos, analisamos três vídeos de diferentes canais de booktubers, caracterizando o booktube como um gênero discursivo.

Este artigo está dividido em cinco seções. Após esta introdução, discutimos, na fundamentação teórica, os conceitos de gêneros do discurso e multimodalidade. Em seguida, apresentamos os pressupostos metodológicos adotados para a seleção dos três vídeos que constituem o corpus, o qual é analisado na seção subsequente. Por fim, apresentamos as considerações finais, nas quais concluímos que o booktube é, de fato, um gênero do discurso e destacamos a sua flexibilidade, pois o booktube admite inserções de estilo individual por parte de quem o produz.

\section{Fundamentação teórica}

Fundamentado no postulado de que todos os campos da atividade humana estão relacionados ao uso da linguagem, que ocorre por meio de enunciados (orais e escritos) concretos e únicos, Bakhtin (2011, p. 262, grifos do autor) propõe que "cada campo de utilização da língua elabora seus tipos relativamente estáveis de enunciados, os quais denominamos gêneros do discurso". Ou seja, os gêneros do discurso estão situados, em tempo e espaço específicos, no campo do qual fazem parte, como ressalta I. Machado (2005); portanto, são determinados por características sociais, históricas e culturais desse campo. 
Dentre essas características, destacam-se os participantes da interação (que alternam os papéis de falante e destinatário ao longo do diálogo) e os possíveis assuntos que podem se tornar objeto dos enunciados. Vale ressaltar que as ações sociais, segundo Dionisio (2011), são fenômenos multimodais, isto é, ocorrem em mais de um modo de representação (verbal oral, verbal escrito, visual, sonoro etc.). Portanto, os gêneros, por serem formas de ação social (MARCUSCHI, 2008), carregam a multimodalidade como uma de suas características.

Com base nas questões socio-histórico-culturais que definem os gêneros discursivos, Bakhtin (2011) afirma que as especificidades de cada campo são refletidas em seu conteúdo (temático), estilo da linguagem e construção composicional. Esses três elementos, sobre os quais comentaremos com mais detalhes posteriormente, "[...] estão indissoluvelmente ligados no todo do enunciado [...]" (BAKHTIN, 2011, p. 262) e são os três pilares básicos que caracterizam os gêneros do discurso.

Os gêneros das novas mídias - que emergem a partir do desenvolvimento e popularização das TDICs e, assim, apresentam especificidades e inovações - lançam desafios à teoria de gêneros do discurso de Bakhtin, pois os estudos do Círculo priorizaram o texto escrito da cultura impressa. No entanto, como Rojo (2013) afirma, trata-se de desafios, mas não de impedimentos. Portanto, neste artigo, assumimos o desafio de caracterizar o booktube como um gênero do discurso, considerando o seu caráter multissemiótico.

Conforme I. Machado (2005), o Círculo de Bakhtin lança uma teoria de análise semiótica capaz de dar conta de enunciações em diversos campos da comunicação humana, incluindo as modernas mídias. Com base nisso, ressaltamos que Bakhtin (2011) reflete sobre usos da linguagem e não somente da língua -, o que dá abertura à expansão de sua teoria. Além disso, o teórico afirma que, em sentido amplo, o texto pode ser entendido como "[...] qualquer conjunto coerente de signos" (BAKHTIN, 2011, p. 307), ou seja, não apenas de signos linguísticos.

É importante salientar, também, que, para a teoria bakhtiniana, a estabilidade dos gêneros é relativa, considerando que as mudanças na sociedade ocasionam transformações nos campos da atividade humana e, consequentemente, nos gêneros do discurso. Nesse sentido, as TDICs foram responsáveis pela reacentuação de diversos gêneros do discurso e pelo surgimento de outros, uma vez que, como Rojo (2013, p. 21) destaca, "a linguagem digital [...] reconfigura todas as modalidades de linguagem e mídias". Com base nisso, Rojo (2013) propõe uma 
V. 11 (3)

386-412

set-dez

2021

ampliação da teoria bakhtiniana de gêneros do discurso, de modo a dar conta dos enunciados multimodais, cada vez mais comuns em nossa sociedade. De acordo com Rojo e Barbosa (2015, p. 108),

texto multimodal ou multissemiótico é aquele que recorre a mais de uma modalidade de linguagem ou a mais de um sistema de signos ou símbolos (semiose) em sua composição. Língua oral e escrita (modalidade verbal), linguagem corporal (gestualidade, danças, performances, vestimentas modalidade gestual), áudio (música e outros sons não verbais - modalidade sonora) e imagens estáticas e em movimento (fotos, ilustrações, grafismos, vídeos, animações - modalidades visuais) compõem hoje os textos da contemporaneidade [...].

Ou seja, os textos - em sentido amplo - que se apresentam em mais de uma modalidade/semiose demandam uma adaptação da teoria bakhtiniana de gêneros do discurso, a fim de que suas especificidades sejam contempladas. Para isso, Rojo (2013) adiciona à situação de comunicação as mídias e tecnologias e expande os conceitos de construção/forma composicional - acrescentando as múltiplas modalidades - e de estilo - reformulando as unidades linguísticas em unidades semióticas, conforme a Figura 1, a seguir, ilustra.

Figura 1 - Elementos da teoria bakhtiniana nos gêneros discursivos das TDICs

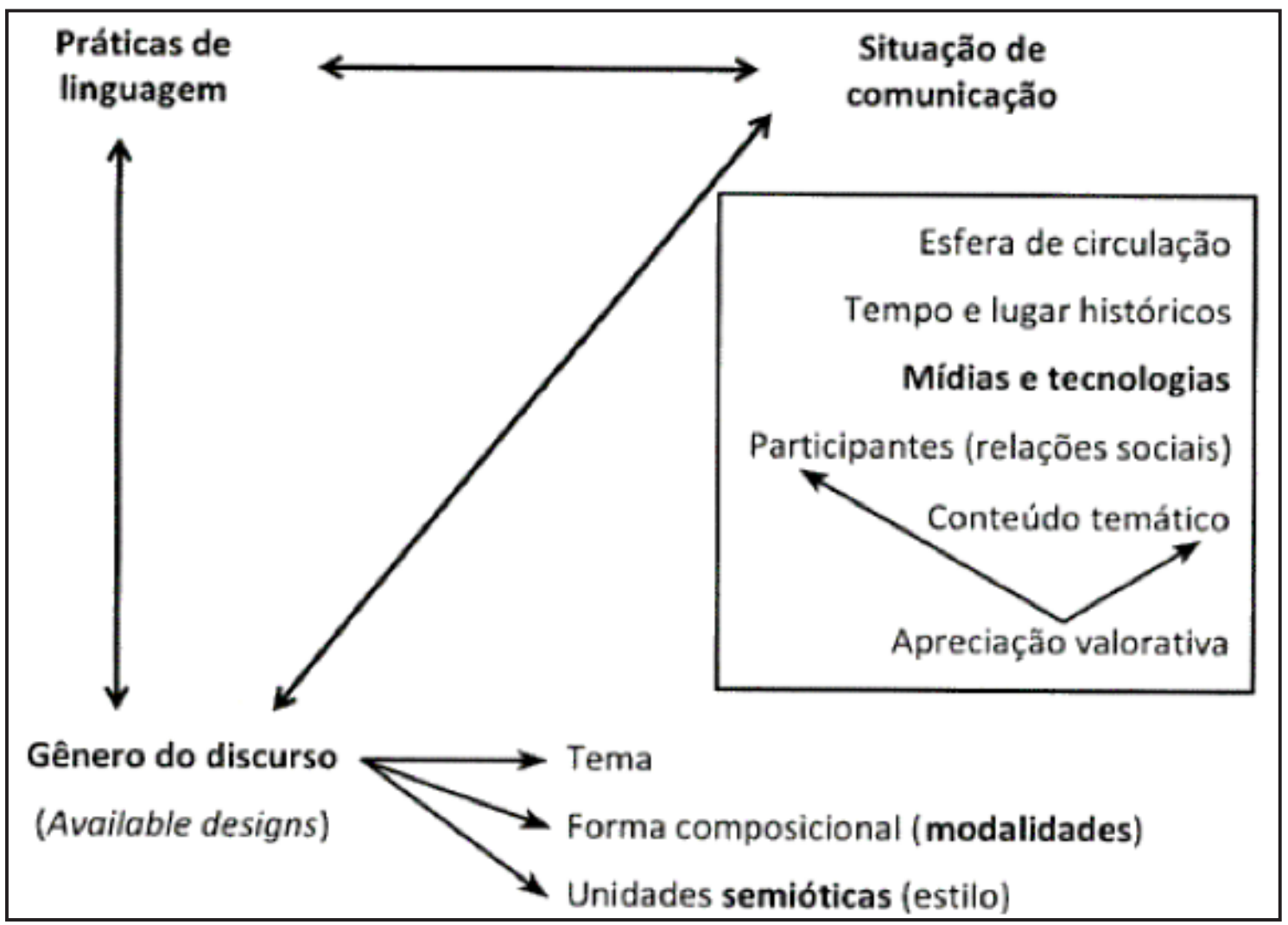

Fonte: Rojo (2013, p. 30). 
Como evidenciado na Figura 1, Rojo (2013) considera que os gêneros do discurso constituem práticas de linguagem que "[...] se dão sempre de maneira situada, isto é, em determinadas situações de enunciação ou de comunicação, que se definem pelo funcionamento de suas esferas ou campos de circulação dos discursos [...]" (ROJO, 2013, p. 27). A situação de comunicação, conforme a autora, é composta pela esfera (campo) de circulação, tempo e lugar históricos, mídias e tecnologias, participantes e respectivas apreciações valorativas. Com base em Bakhtin e nas características dos gêneros das TDICs, Rojo (2013) assume que os gêneros do discurso são formados por um tema (conteúdo temático), uma forma (construção) composicional - que inclui diferentes modalidades - e um estilo - formado por diversas unidades semióticas. Vejamos, a seguir, em que consiste cada um desses pilares, conforme os postulados de Bakhtin (2011) e sua ampliação feita por Rojo (2013).

Como já mencionamos, os gêneros do discurso são definidos por Bakhtin (2011, p. 262, grifo do autor) como "[...] tipos relativamente estáveis de enunciados [...]", que refletem as condições específicas dos diversos campos da atividade humana a partir de três elementos indissociáveis: conteúdo temático, estilo e construção composicional. Segundo Sobral (2009), quando se fala em gênero discursivo do ponto de vista relativamente estável, compreende-se que ora ele conserva traços que o identificam como tal, ora ele se transforma e é alterado cada vez que é empregado, "[...] havendo mesmo casos em que um gênero de transforma em outro" (SOBRAL, 2009, p. 115), como ocorre com os pares carta/e-mail, conversa/chat e diário/blog - citados por Rojo e Barbosa (2015) - , por exemplo. A seguir, expomos, separadamente, do que se trata cada um dos elementos que Bakhtin utiliza para alicerçar a definição de gêneros do discurso.

De acordo com Bakhtin (2011, p. 289), "cada enunciado se caracteriza, antes de tudo, por um determinado conteúdo semânticoobjetal", isto é, por um determinado assunto, o qual, apesar de ser inesgotável, ganha uma relativa conclusibilidade ao se tornar tema do enunciado. O conteúdo temático não se limita ao assunto abordado no enunciado, pois diz respeito à apreciação valorativa do falante acerca do assunto, a qual se manifesta por meio da concretização de sua vontade discursiva. Segundo Ribeiro (2010, p. 57, grifos da autora), esse elemento "[...] cumpriria o papel de orientador da comunicação discursiva", visto que desencadeia, na cena da enunciação, múltiplos 
V. $11(3)$ $386-412$ set-dez 2021

sentidos concernentes a outros enunciados que surgem no evento comunicativo. Assim, Bakhtin (2011, p. 289) propõe que "a relação valorativa do falante com o objeto do seu discurso (seja qual for esse objeto) também determina a escolha dos recursos lexicais, gramaticais e composicionais do enunciado", como veremos a seguir.

Conforme Ribeiro (2010), todo ato comunicativo se realiza por meio de um formato que cumpre a função de integrar, sustentar e ordenar as propriedades do gênero. Nesse sentido, a construção composicional refere-se à estrutura, ou seja, à "[...] organização e [a]o acabamento de todo o enunciado, do texto como um todo" (ROJO; BARBOSA, 2015, p. 94). O acabamento de um gênero, pode se dar, por exemplo, em versos ou parágrafos, ser dividido em seções específicas etc. Essa característica demonstra, de certo modo, a multimodalidade intrínseca a todos os gêneros, uma vez que, como aponta Dionisio (2011), as palavras sempre vêm acompanhadas de outro modo de representação - a exemplo de entonação, expressão facial e gestos, no caso da oralidade, e de imagens e aspectos tipográficos, no caso da escrita. Acrescentamos, ainda, que a aplicação desse conceito a gêneros orais - ou, efetivamente, audiovisuais, tendo em vista a multimodalidade intrínseca - , como o booktube, torna necessário considerar, simultaneamente, elementos de ordem linguística (oral e escrita), sonora e visual em sua caracterização. É importante destacar que a construção composicional é determinada pela "[...] relação subjetiva emocionalmente valorativa do falante com o conteúdo do objeto e do sentido do seu enunciado" (BAKHTIN, 2011, p. 289), que também designa o estilo.

Bakhtin (2011, p. 266) salienta que "o estilo é indissociável de determinadas unidades temáticas e - o que é de especial importância de determinadas unidades composicionais". Portanto, para fazer ecoar sua vontade discursiva, o falante realiza, além das escolhas estruturais, mencionadas acima, determinadas escolhas lexicais e gramaticais, o que, segundo Bakhtin (2011), consiste no estilo de linguagem. O teórico ressalta, porém, que "todo enunciado [...] é individual e por isso pode refletir a individualidade do falante (ou de quem escreve), isto é, pode ter estilo individual" (BAKHTIN, 2011, p. 265, grifo nosso).

Segundo Ribeiro (2010), o estilo individual decorre das singularidades do sujeito enunciador e de suas escolhas particulares na dinâmica discursiva e é fruto da confluência dos usos linguísticos, textuais e discursivos. Vale ressaltar, aqui, que, mesmo que um gênero aparente possuir apenas uma modalidade semiótica, se analisarmos 
detidamente, verificaremos que isso não ocorre (DIONISIO, 2011). A título de exemplo, percebamos que, assim como a língua oral enunciada no gênero conversa do cotidiano é atravessada por outras semioses, tais como os gestos e as imagens, o mesmo também ocorre com o gênero booktube, por meio dessas ou de outras semioses, como os sons e as imagens, por exemplo.

Devido a isso, estendemos a noção de estilo às seleções de elementos multissemióticos/multimodais realizadas pelos falantes, uma vez que o sentido não é estabelecido apenas por meio de aspectos linguísticos, mas também por elementos sonoros, gestuais e visuais, como salientam Rojo e Barbosa (2015). Dessa maneira, em virtude da multimodalidade intrínseca aos textos e, especialmente, das novas tecnologias, ampliamos a compreensão do pilar de estilo, de modo a retirar a linguagem escrita da centralidade e dar lugar a outras modalidades.

Além disso, Dionisio (2011) ressalta, ainda, que a multimodalidade, nos diferentes gêneros, ocorre em níveis variados, dentro de um contínuo. Essa afirmação vai ao encontro do pressuposto de Bakhtin (2011) em relação à (não) flexibilidade dos gêneros e à manifestação do estilo individual. Para o autor, há gêneros mais ou menos propícios a reflexos da individualidade, ou seja, em alguns gêneros, há espaço para matizes de entonação expressiva que refletem o estilo individual do falante, ao passo que, em outros, o estilo do gênero prevalece. Com isso, reafirma-se que o estilo e a construção composicional são marcas linguístico-textuais - e multissemióticas das apreciações valorativas do falante, como ressaltam Rojo e Barbosa (2015).

Diante da heterogeneidade de gêneros do discurso, Bakhtin (2011) propõe uma classificação em duas categorias: primários e secundários. A diferença essencial entre elas, conforme o teórico, não é de natureza funcional, mas determinada em relação às condições de produção e de convívio cultural em que cada gênero é produzido. Dessa forma, os gêneros primários são considerados mais simples, visto que nascem em condições de comunicação discursiva mais imediata, cotidiana, e geralmente ocorrem na modalidade oral, ao passo que os gêneros secundários são tidos como complexos, pois "[...] surgem nas condições de um convívio cultural mais complexo e relativamente muito desenvolvido e organizado" (BAKHTIN, 2011, p. 263), em geral, na modalidade escrita. 
V. 11 (3)

386-412

set-dez

2021

Bakhtin (2011) aponta, ainda, que os gêneros secundários, em seu processo de formação, incorporam e reelaboram gêneros primários. Com base nisso, Faraco (2009) salienta que a classificação dos gêneros em primários e secundários não deve ser observada em uma perspectiva dicotômica, visto que os dois tipos de gêneros estão inter-relacionados e, muitas vezes, um influencia o outro. A partir da observação de determinadas coerções sociais, históricas e culturais, acrescentamos que, com o surgimento de novos gêneros, proporcionado pelas TDICs, é possível expandir a categorização de gêneros primários e secundários aos chamados gêneros discursivos digitais. Nesse sentido, destacamos que, de acordo com Araújo (2010, p. 114), há "[...] casos em que os gêneros secundários, para se formarem, também transmutam outros secundários, e esses casos não foram previstos por Bakhtin".

Nossa hipótese é de que esse seja o caso dos booktubes, visto que esses vídeos, conforme Carpintéro (2019), apresentam divulgações de resenhas literárias. A resenha é um gênero secundário que circula comumente nos campos jornalístico e acadêmico. MottaRoth e Hendges (2010, p. 28) explicam que "para atender o leitor, o resenhador basicamente descreve e avalia uma dada obra a partir de um ponto de vista informado pelo conhecimento produzido anteriormente sobre aquele tema". Para tal, segundo as autoras, na elaboração de uma resenha, deve-se seguir quatro etapas, que se apresentam em extensão e frequência variadas: apresentar > descrever > avaliar > (não) recomendar o livro.

Com base nessas considerações, buscamos caracterizar o booktube como um gênero discursivo, avaliando seu conteúdo temático, estilo e construção composicional. Para isso, fundamentamo-nos nas categorias bakhtinianas e em sua ampliação, feita por Rojo (2013), bem como nos pressupostos de Dionisio (2011) e Rojo e Barbosa (2015) acerca da multimodalidade. Na próxima seção, apresentamos os pressupostos metodológicos adotados para nossa investigação e, em seguida, os resultados e a discussão da análise empreendida.

\section{Pressupostos metodológicos}

Para compor o corpus do trabalho, selecionamos três vídeos de booktubers publicados em canais da plataforma YouTube:

(i) "VEDA \#7: Resenha O Mágico de Oz", do canal Leituras de Deni; 
(ii) "Alice No País Das Maravilhas, Lewis Carroll (\#18)", do canal Ler Antes de Morrer; e

(iii) "[RESENHA] O Mágico de Oz", publicado no canal Literature-se.

Para análise dos vídeos, transcrevemos fragmentos das falas dessas booktubers, com base em normas de transcrição estabelecidas por Marcuschi (2003), apontando os devidos comentários e descrições das unidades semióticas concomitantes à fala, a fim de verificar minuciosamente as regularidades do booktube como gênero discursivo, considerando sua multimodalidade. Tais informações foram lançadas em um quadro comparativo, com tópicos referentes ao conteúdo temático, construção composicional e estilo (semiótico), à luz da teoria bakhtiniana dos gêneros discursivos, enquanto elementos indissociáveis e relativamente estáveis, ampliada por Rojo (2013) no tocante à análise de elementos multimodais. É o resultado desta investigação que mostramos a seguir.

\section{Resultados e discussão}

Partindo da concepção de que tudo o que dizemos, pensamos ou escrevemos mediante a linguagem acontece por meio de enunciados relativamente estáveis, ou seja, de gêneros, defendemos que o booktube é um gênero discursivo digital multimodal, ocasionado pelas TDICs. Embora não encontremos nenhum material publicado que admitisse o booktube como gênero discursivo, dispomo-nos a realizar essa tarefa.

Como mencionamos na seção anterior, o corpus deste artigo é formado por booktubes de três diferentes canais do YouTube: Leituras de Deni (Deni), Ler Antes de Morrer (Isabela Lubrano) e Literature-se (Mel Ferraz), que circulam em ambiente digital, no âmbito do campo artístico-literário ${ }^{2}$, produzindo cultura, arte e entretenimento na contemporaneidade.

Conforme Bakhtin (2011), os três elementos integrantes dos gêneros discursivos - conteúdo temático, construção composicional e estilo - são indissociáveis uns dos outros, pois os conteúdos temáticos dos enunciados se realizam somente a partir de uma construção composicional e um estilo específico. Logo, a separação entre os três elementos foi realizada apenas para efeito de análise.

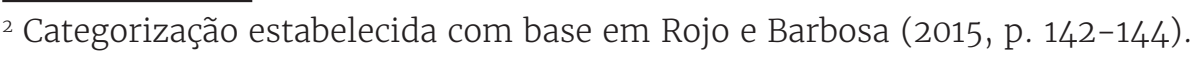


V. 11 (3)

386-412

set-dez

2021

Mostramos, de forma sistemática, no Quadro 1, o conteúdo temático de cada booktube analisado; contudo, sabendo que, para Bakhtin (2011), o tema consiste no conteúdo inferido com base na apreciação valorativa do locutor. Esses acentos valorativos das booktubers serão evidenciados quando apresentarmos a construção composicional e o estilo de cada uma dessas produtoras de conteúdo, no decorrer desta análise.

Quadro 1 - Conteúdo temático dos booktubes analisados

\begin{tabular}{|c|c|c|c|}
\hline \multirow{3}{*}{ 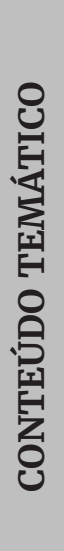 } & \multicolumn{3}{|c|}{ CANAIS DE BOOKTUBERS } \\
\hline & $\begin{array}{l}\text { VEDA \#7: Resenha O } \\
\text { Mágico de Oz } \\
\text { Canal LEITURAS DE } \\
\text { DENI (Deni) }\end{array}$ & $\begin{array}{c}\text { Alice No País Das } \\
\text { Maravilhas, Lewis } \\
\text { Carroll (\#18) } \\
\text { Canal LER ANTES } \\
\text { DE MORRER (Isabela } \\
\text { Lubrano) }\end{array}$ & $\begin{array}{l}\text { [Resenha] O Mágico de } \\
\text { Oz. } \\
\text { Canal LITERATURE-SE } \\
\text { (Mel Ferraz) }\end{array}$ \\
\hline & $\begin{array}{l}\text { Resumo e apreciação } \\
\text { valorativa positiva } \\
\text { do clássico infantil O } \\
\text { Mágico de OZ. }\end{array}$ & $\begin{array}{c}\text { Resumo e apreciação } \\
\text { valorativa positiva do } \\
\text { clássico infantil Alice no } \\
\text { País das Maravilhas e da } \\
\text { vida do seu autor. }\end{array}$ & $\begin{array}{l}\text { Resumo e apreciação } \\
\text { valorativa positiva } \\
\text { do clássico infantil O } \\
\text { Mágico de OZ. }\end{array}$ \\
\hline
\end{tabular}

Constatamos que o conteúdo temático dos booktubes em questão, ou seja, a apreciação valorativa do assunto enunciado nessas produções é relativamente estável no campo artístico-literário, visto que as booktubers utilizam a plataforma de vídeos como canal de socialização de suas avaliações/impressões a respeito dos clássicos infantis em questão.

Nesta análise, identificamos que, se por um lado o conteúdo temático do gênero é estável, por outro ele é variável, como defende Sobral (2009). A estabilidade justifica-se pelo fato de, na produção do gênero booktube, as enunciadoras mobilizarem como assunto principal a sumarização e avaliação de obras do campo artístico-literário do universo infantil. A parte variável, por sua vez, está relacionada à reflexão de suas experiências enquanto sujeitos sociais, expressas por meio de vocábulos ou pela ausência deles; ou seja, cada uma das booktubers imprime significados únicos aos seus enunciados. Ressaltamos, nesse sentido, que Sobral (2009) reforça que os significados do conteúdo temático são concretos e dinâmicos, porque sujeitos diferentes inseridos em novos contextos criam temas inéditos.

Ribeiro (2010) pontua que, para analisar o conteúdo temático 
de um determinado gênero, é imprescindível considerar tanto aspectos linguísticos quanto aspectos enunciativos e discursivos, ou seja, deve-se levar em conta o papel desses sujeitos no decorrer dos acontecimentos sócio-históricos que os atravessaram. Nas produções analisadas, por exemplo, vimos que as booktubers abordam obras clássicas do universo infantil: Alice no País das Maravilhas e O Mágico de Oz, sendo que dois desses canais - Leituras de Deni e Literature-se - booktualizam a mesma obra. Apesar de se referirem ao mesmo assunto, os conteúdos temáticos dessas produções são únicos e irrepetíveis, visto que os sentidos de cada um desses enunciados estão carregados pelo acúmulo de valores ideológicos adquiridos em determinados tempos, espaços e culturas, ao longo da trajetória de cada uma dessas enunciadoras. Tais aspectos são percebidos por meio da construção composicional e do estilo (semiótico) de cada uma delas.

Também constatamos que, se os conteúdos temáticos são variáveis, também variam a construção composicional e as escolhas semióticas (estilo) que são feitas pelas booktubers para tratarem o tema sobre o qual pretendem enunciar. No entanto, consideramos, com base em Marcuschi (2008), que há um saber social comum, denominado de competência textual, que nos permite reconhecer os gêneros quando estamos diante de seus exemplares. Com relação ao formato de composição que os enunciados das booktubers tiveram, evidenciamos as seguintes estruturas, numeradas em ordem de apresentação por numerais cardinais, conforme se vê no Quadro 2. 
V. 11 (3)

$386-412$

set-dez

2021

Quadro 2 - Construção composicional dos booktubes analisados

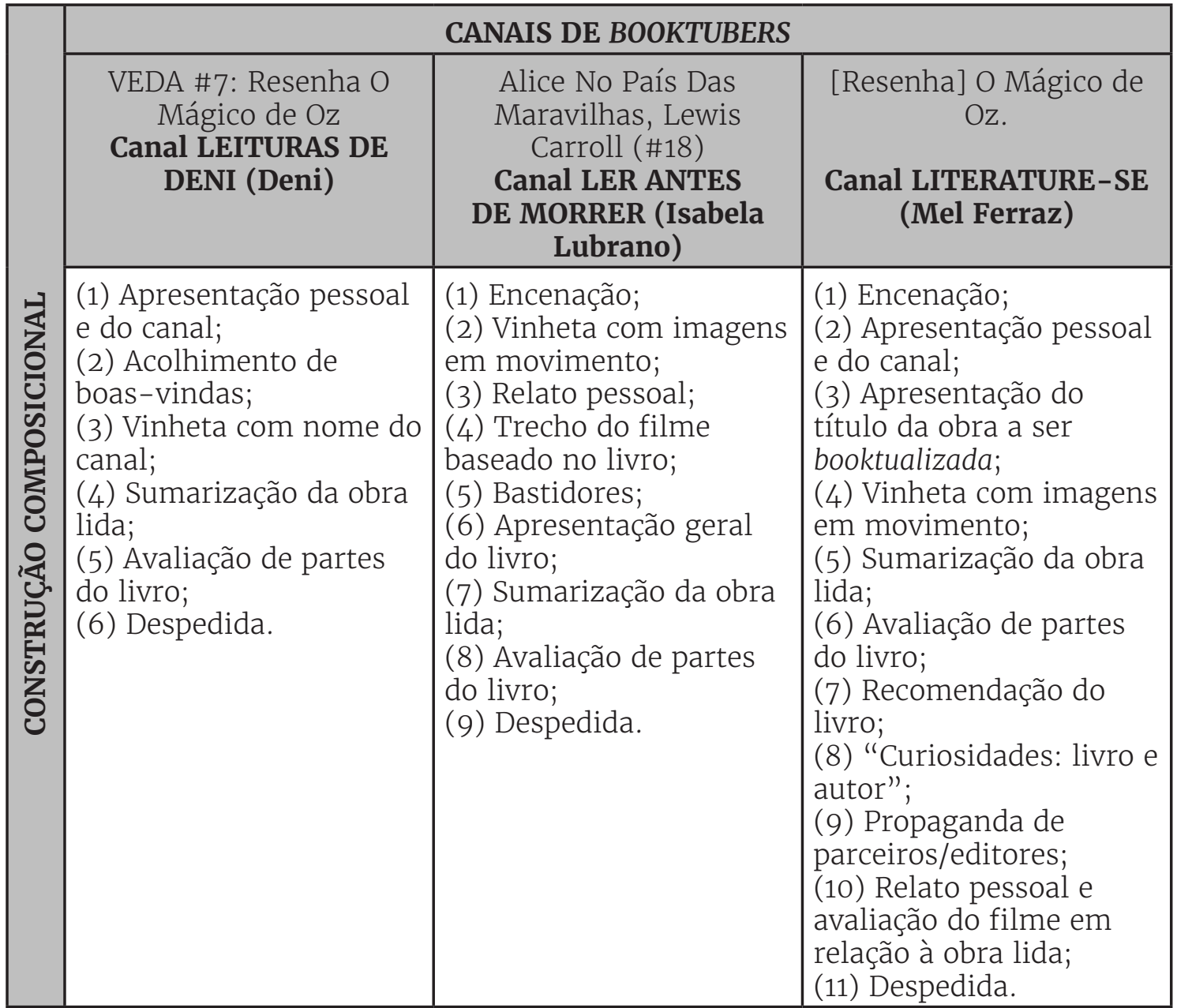

Fonte: Elaboração própria.

Com base nas informações contidas no Quadro 2, constatamos regularidades no que se refere à construção composicional do booktube por meio de cinco elementos, que se repetem nas três produções: (1) vinhetas estáticas ou em movimento para apresentar o título do canal ou da obra booktualizada; (2) apresentação pessoal/do canal; (3) sumarização da obra; (4) avaliação da obra lida; e (5) despedida. Os elementos 1, 2 e 5 são breves, portanto, ocupam poucos segundos dos vídeos, ao passo que os elementos 3 e 4 são os de maior duração nos booktubes e podem aparecer concomitantemente - a depender do estilo individual das booktubers. Essa ocorrência comprova o postulado bakhtiniano de que a construção composicional do gênero reflete a vontade discursiva do falante no enunciado.

Considerando que a função do booktube é avaliar uma obra literária, é plausível que as etapas de sumarização e avaliação da obra booktualizada sejam predominantes na estrutura do gênero. De acordo com A. Machado (2010, p. 161), "o processo de sumarização é condição 
fundamental para a mobilização de conteúdos pertinentes para a produção de textos pertencentes a diferentes gêneros, como resenhas, contracapas e reportagens". A autora explica que a sumarização ocorre a partir de estratégias de apagamento - que consiste na seleção de ideias mais relevantes e, consequentemente, descarte de informações menos necessárias - e de substituição - que exigem novas construções linguísticas para expressar, com outras palavras, o conteúdo do texto-base, por meio de generalizações ou de construções a partir de inferências. A avaliação, por sua vez, diz respeito à exposição da apreciação valorativa acerca do assunto. No caso do booktube, essa ação ocorre no instante em que o enunciador elenca pontos específicos da obra, conforme suas leituras prévias e a natureza dos temas que se propõe a evidenciar, a exemplo de: vida e obra do autor, polêmicas, curiosidades, relatos pessoais etc. Tais elementos não aparecem nos três vídeos analisados, o que nos leva a considerá-los como aspectos flexíveis do gênero e, portanto, como marcas de estilo individual.

No entanto, destacamos que essas estruturas são relativamente estáveis, ou seja, ao mesmo tempo estáveis e mutáveis, visto que não se constatou nas produções analisadas uma forma composicional rígida e, muito menos, estática. A mutabilidade/dinamicidade desse gênero explica-se pelo fato de a sua construção composicional mudar de acordo com o projeto enunciativo de cada uma das booktubers. No que se refere à estrutura composicional dos booktubes analisados, em específico, vejamos, agora, os aspectos que aparecem em cada um dos vídeos produzidos.

A construção composicional do booktube produzido pelo canal Leituras da Deni para tratar do livro O Mágico de Oz, por exemplo, tem duração de 4 minutos e 59 segundos e, por isso, propõe-se a configurar, de maneira mais objetiva e direta, os seguintes elementos: (1) apresentação pessoal; (2) acolhimento de boas-vindas; (3) vinheta com nome do canal; (4) sumarização da obra lida; (5) avaliação de partes do livro; e (6) despedida. Apesar de apresentar um vídeo mais curto, ela seleciona para a composição da sua produção digital o elemento "acolhimento de boas-vindas" na abertura de seu vídeo, diferentemente dos canais Ler Antes de Morrer e Literature-se.

O vídeo do canal Ler Antes de Morrer, da booktuber Isabela Lubrano, produzido com intuito de booktualizar o livro Alice no País das Maravilhas, tem duração intermediária, em relação aos outros dois - 9 minutos e 40 segundos. Embora ele apresente elementos em comum 
V. $11(3)$

$386-412$

set-dez

2021

com os demais, visualiza-se uma construção composicional um pouco divergente: (1) encenação; (2) vinheta com imagens em movimento; (3) relato pessoal; (4) trecho do filme; (5) bastidores; (6) apresentação geral do livro; (7) sumarização da obra lida; (8) avaliação de partes do livro; e (9) despedida. Nessa produção, dois elementos nos chamam a atenção: (i) a encenação, elaborada no início do vídeo, a partir das escolhas semióticas da booktuber, e (ii) a abrangência de tratamento do tema pela booktuber, visto que ela realiza valorações apreciativas não apenas em função da obra, propriamente dita, mas também em relação ao seu contexto de produção e a questões concernentes à vida do autor.

Por fim, o vídeo do canal Literature-se, de Mel Ferraz, tem duração de 18 minutos e 39 segundos e, assim como os analisados anteriormente, apresenta elementos divergentes no tocante à construção composicional. Vejamos: (1) encenação; (2) apresentação pessoal e do canal; (3) apresentação do título da obra a ser booktualizada; (4) vinheta com imagens em movimento; (5) sumarização da obra lida; (6) avaliação de partes do livro; (7) recomendação do livro; (8) "Curiosidades: livro e autor"; (9) propaganda de parceiros/editores; (10) relato pessoal e apreciação valorativa do filme, em comparação com a obra lida; e (11) despedida.

Diante do exposto, vimos que cada booktuber modela a construção composicional do gênero e a ela agrega elementos (multi) semióticos, refletindo suas individualidades. Além disso, constatamos diferentes ações de linguagem atuando concomitantemente na construção composicional do gênero. As booktubers Mel Ferraz e Isabela Lubrano, por exemplo, lançam mão de sumarizações e avaliações sem necessariamente seguir uma estrutura rígida. Cada uma delas cria seções informativas, conforme suas experiências sócio-históricas, sobre o assunto enunciado.

No tocante à estabilidade da estrutura composicional do gênero, percebe-se que ele é estável porque conserva traços que o identificam como tal e é mutável porque está em constante transformação, passando por modificações cada vez que é empregado (SOBRAL, 2009). As regularidades do booktube, por exemplo, mostram que ele é fruto da transformação do gênero escrito resenha, que, em virtude da popularidade das TDICs, materializa-se no formato do gênero booktube. Motta-Roth e Hendges (2010) explicam, que, em geral, uma resenha apresenta determinada ordem de ações: (1) apresentar; (2) descrever; (3) avaliar e/ou (4) (não) recomendar. As autoras salientam 
que esse gênero pode apresentar variações tanto na estrutura (extensão), quanto no estilo (ser mais ou menos resumidor, crítico ou avaliador), a depender dos objetivos do resenhador e de qual ênfase ele deseja dar ao texto lido. Logo, não há "[...] uma norma a ser seguida cegamente" (MOTTA-ROTH; HENDGES, 2010, p. 29).

Além disso, segundo Faraco (2009, p. 127), "o repertório de gêneros de cada esfera da atividade humana vai diferenciando-se e ampliando-se à medida que a própria esfera se desenvolve". A análise empreendida neste estudo mostra que o gênero booktube apresenta indícios da estrutura da resenha, que passou por modificações ao ser transformada em vídeo. A partir da descrição de ações da elaboração do vídeo de cada booktuber, traçamos uma descrição esquemática de ações regulares na estrutura composicional do gênero e identificamos, por exemplo, seções de apresentação do autor, sumarização/descrição e avaliação da obra sobre a qual se comenta - elementos comuns, também, no gênero resenha.

No que concerne ao estilo, terceiro elemento do gênero discursivo, Bakhtin (2011, p. 265) postula que "nem todos os gêneros são igualmente propícios a tal reflexo da individualidade do falante na linguagem do enunciado". Isso não ocorre com o booktube, visto que ele é um gênero mais flexível, que permite a inserção do estilo individual de quem o produz, tanto por meio de recursos linguísticos quanto por meio de recursos semióticos, como veremos adiante.

Rojo e Barbosa (2015), com base em Bakhtin (2011), ressaltam que o estilo é indissociável do conteúdo temático e da construção composicional do enunciado. Assim também compreendemos a análise do estilo e, por se tratar de um elemento de maior abrangência visto que, além de poder apresentar, simultaneamente, diferentes linguagens, dada a multimodalidade presente em todos os gêneros (DIONISIO, 2011), há a possibilidade de manifestação do estilo individual - , não pretendemos o esgotamento de todas as unidades semióticas encontradas nos booktubes analisados. Por isso, selecionamos apenas alguns dos fragmentos da transcrição que descrevam exemplos dos diversos elementos multimodais (linguísticos, sonoros, gestuais e visuais) presentes no contexto de produção do gênero em análise.

Para sistematizar a análise do estilo, apoiamo-nos nas modalidades verbal, gestual, sonora e visual, com base na definição de texto multissemiótico/multimodal feita por Rojo e Barbosa (2015), na qual as autoras ressaltam a co-ocorrência dessas quatro modalidades 
v. $11(3)$

$386-412$

set-dez

2021 nos textos da contemporaneidade. No Quadro 3, a seguir, compendiamos as unidades (multi)semióticas utilizadas pelas respectivas booktubers em suas produções.

Quadro 3 - Estilo: unidades semióticas dos booktubes analisados 


\begin{tabular}{|c|c|c|c|c|}
\hline \multirow{2}{*}{ 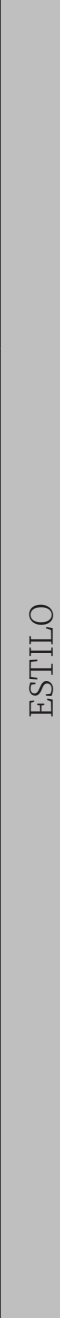 } & 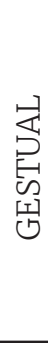 & $\begin{array}{l}\text { a) Jogando beijo na } \\
\text { despedida; } \\
\text { b) Dedos indicadores } \\
\text { de ambas as mãos } \\
\text { apontados para baixo. }\end{array}$ & $\begin{array}{l}\text { a) Dedos indicador e } \\
\text { médio gesticulados para } \\
\text { indicar o numeral dois; } \\
\text { b) Dedos indicadores } \\
\text { de ambas as mãos } \\
\text { sinalizando o local onde } \\
\text { se encontra o botão } \\
\text { "inscrever-se". }\end{array}$ & $\begin{array}{l}\text { a) Sinal de aspas com } \\
\text { dedos indicador e médio; } \\
\text { b) Dedo indicador } \\
\text { apontado para a cabeça } \\
\text { para se referir à força } \\
\text { psicológica de Dorothy. }\end{array}$ \\
\hline & 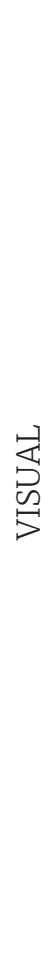 & $\begin{array}{l}\text { a) Efeito de transição } \\
\text { fade para preto3, para } \\
\text { demarcar a mudança de } \\
\text { tópicos; } \\
\text { b) Legenda remetendo ao } \\
\text { botão "Inscrever-se"; } \\
\text { c) Legendas: hashtags; } \\
\text { d) Versão impressa } \\
\text { do livro booktualizado } \\
\text { suspensa em mãos, } \\
\text { durante todo o vídeo; } \\
\text { e) Vinheta estática com } \\
\text { nome do canal; } \\
\text { f) Plano de fundo: } \\
\text { estante de livros com } \\
\text { impressos organizados } \\
\text { na vertical e horizontal e } \\
\text { outros enfeites dispostos. }\end{array}$ & $\begin{array}{l}\text { a) Bastidores demarcados } \\
\text { em cenas nas cores preto } \\
\text { e branco; } \\
\text { b) Imagens em } \\
\text { movimento: ilustrações e } \\
\text { animações do filme Alice } \\
\text { no país das maravilhas; } \\
\text { c) Imagem em } \\
\text { movimento de sinal de } \\
\text { TV fora do ar; } \\
\text { d) Imagens estáticas: } \\
\text { fotos e pinturas do autor } \\
\text { Lewis Carroll; } \\
\text { e) Versão impressa do } \\
\text { livro booktualizado em } \\
\text { mãos; } \\
\text { f) Vinheta com imagens } \\
\text { em movimento, nome do } \\
\text { canal e da booktuber; } \\
\text { g) Plano de fundo: } \\
\text { estante de livros com } \\
\text { impressos organizados } \\
\text { na vertical. }\end{array}$ & $\begin{array}{l}\text { a) Bastidores demarcados } \\
\text { em cenas nas cores preto } \\
\text { e branco; } \\
\text { b) Vinhetas com imagens } \\
\text { em movimento e título } \\
\text { do canal e da obra } \\
\text { booktualizada; } \\
\text { c) Plano de fundo: } \\
\text { estante de livros com } \\
\text { impressos organizados } \\
\text { na vertical; } \\
\text { d) Versão impressa } \\
\text { do livro booktualizado } \\
\text { em mãos (em alguns } \\
\text { momentos). }\end{array}$ \\
\hline
\end{tabular}

Fonte: Elaboração própria.

Como já mencionamos, o texto multimodal, envolvendo diversas linguagens, tais como as unidades enquadradas no Quadro 3, colocam alguns desafios para a teoria dos gêneros discursivos. Considerando que booktube é um gênero altamente multimodal, uma vez que é composto tanto por linguagem verbal oral quanto por elementos de outras linguagens, realizamos transcrições de trechos de falas, gestos, sons e imagens presentes no booktube, com o intuito de evidenciar elementos constitutivos do sistema multimodal, relevantes na ressonância de vozes e sentidos dos enunciados, ou seja, nos seus conteúdos temáticos.

A análise das unidades comunicativas próprias da modalidade verbal oral serão apresentadas conforme os marcadores conversacionais categorizados por Marcuschi (2003). Nos excertos a seguir, elencaremos os sinais conversacionais mais recorrentes, utilizados com a funcionalidade de sustentar o turno de fala, instaurar pausas sintáticas

\footnotetext{
${ }^{3}$ Categorização elaborada com base no software Movavi Video Suite 2020.
} 
V. 11 (3) $386-412$ set-dez 2021

e/ou não-sintáticas, e, além disso, fazer ecoar suas apreciações valorativas a respeito dos livros booktualizados.

Os sinais conversacionais utilizados pelas booktubers para sustentar o turno de fala são percebidos, com maior recorrência, ao longo das produções de duas delas, como constatamos nos fragmentos de falas de Isabela Lubrano e Mel Ferraz. No entanto, esses elementos também são perceptíveis na transcrição de fala de Deni. Vejamos.

Deni: Olá, tudo bem" Eu sou a Deni, sejam muito bem vindo a leituras da Deni e ao sétimo dia do /.../ e HOje a gente tem a resenha de:: O Mágico de Oz: (9.0) ((paralelo à pausa exibe-se a vinheta estática com nome do canal)) E nO Mágico de Oz, a gente tem a história da DoroTHY, do leÃ::o /.../

Mel Ferraz: Bo::m, o Mágico de Oz conta a história de de Dortothy Gale, que é uma garota (+) uma criança, na verdade, né" $(+)$ que aqui:: ((apontando para o livro, que está suspenso em mãos)) (+) /.../ Bo::m (+) ela é uma órfã que mora com seus tios e seu cachorro chamado Totó /... /

Isabela Lubrano: Olha só que antigo, tá vendo" $(+)$ Eu acho que é de antes de ele vir para o Brasil (+) aqueles relógios de bolso, né" (+) /.../

Nos fragmentos acima, as palavras que se encontram em destaque exemplificam os sinais de sustentação de turno utilizados pelas falantes para manter a palavra e conseguir o assentimento dos ouvintes, mesmo que eles não estejam presentes no diálogo face a face. De acordo com Marcuschi (2003), esses sinais costumam aparecer no início do turno, marcados por palavras como "e" "olha", "bom", "eu acho", bem como pelas expressões utilizadas pelas booktubers do decorrer do booktube; e no final dele, marcados por palavras como "né?", "certo?", "viu" e outras. As diferenças de marcadores conversacionais presentes em um discurso demarcam a diferença de registro linguístico mais ou menos (in)formal.

Outro elemento comum às práticas orais, a ser descortinado com base nos fragmentos acima, são as pausas sintáticas. Conforme Marcuschi (2003), pausas e silêncios são indicados entre parênteses: pausas pequenas são marcadas pelo sinal "+" para cada 0.5 segundo; 
enquanto, em pausas além de 1.5 segundo, indica-se o tempo cronometrado. No seguinte fragmento de transcrição, constata-se a presença de uma pausa sintática: "Bo::m, o Mágico de Oz conta a história de de Dortothy Gale, que é uma garota (+) uma criança, na verdade, né"'"; pois, a marcação de pausa, nesse caso, exerce a função coesiva de encadear enunciados distintos com objetivo de redefinir/ corrigir o conteúdo enunciado. Nesse caso, poderíamos substituir, sem prejuízo de sentido, a pausa (+) pela expressão "ou melhor", vejamos: "Bo::m, o Mágico de Oz conta a história de de Dortothy Gale, que é uma garota, ou melhor, uma criança, na verdade, né"”".

Ainda com relação à função da pausa, percebamos, a partir da transcrição do booktube de Deni, que, paralelamente às pausas, a produtora inseriu elementos visuais com o intuito de demarcar a mudança de tópicos: "E nO Mágico de Oz, a gente tem a história da DoroTHY, do leÂ::o, do homem de lata e do espantalho, em busca de seus desejos (++) ((paralelamente à pausa, utiliza-se o efeito de transição fade para preto para demarcar a mudança de tópicos))". Vê-se que o elemento descrito entre parênteses pertence à modalidade visual e é apenas um exemplo dentre as inúmeras possibilidades de unidades semióticas dispostas nos vídeos analisados. Essas variações se dão em função da construção composicional e do estilo individual da booktuber, que, conforme já dissemos, reflete a apreciação valorativa das produtoras.

Os elementos linguísticos são fundamentais para a elaboração dos booktubes, e sua presença é caracterizada não apenas pelos marcadores de conversação, mas também pela língua escrita utilizada nas mais diversas legendas que surgem sobrepostas às telas, ao mesmo tempo em que as booktubers discursivizam sobre o conteúdo temático. Essas legendas servem para mostrar os nomes dos canais, apresentar os títulos das obras booktualizadas, reforçar enunciados orais, disponibilizar hiperlinks de websites e potencializar comandos como: "curta, compartilhe e inscreva-se", conforme demonstram os seguintes destaques dos trechos transcritos.

Deni: ... (+) e:: espero ver vocês no próximo vídeo (+) que é A:manhã (+) Não se esqueçam de se inscrever no canal, o botão fica aqui embaixo ((booktuber utiliza dedos indicadores, de ambas mãos, para sinalizar para baixo concomitantemente a legenda "inscrever-se" que aparece sobreposta ao vídeo)) $|\ldots|$ 
V. 11 (3)

$386-412$

set-dez 2021

Isabela Lubrano: E não pense que isso é alguma coisa (+) e nem uma coisa ra-zo-a-velmente Antiga, inventada pelo Walt Disney, nos anos mil novecentos e cinquenta (+) não (+) porque foi no ano de: $(+)$ mil oi-to-centos e SESsenta e cinco ((aparece legenda com numeral cardinal 1965)) que:: /.../ |...|

Mel Ferraz: Eu indico fortemente (+) ele é muito profundo /.../ se inscrevam no canal, acessem o blog que vai está aparecendo na tela agora mesmo ((aparece legenda com endereço do website do blog Literature-se)) e até o próximo vídeo (+) tchau, tchau.

Não podemos nos esquecer de que as apreciações valorativas das booktubers, em relação aos livros booktualizados, constroem-se por meio dos recursos linguísticos - tanto orais quanto escritos - que se imbricam a outras unidades semióticas, tais como as sonoras, gestuais e visuais, as quais, conforme Rojo e Barbosa (2015, p. 108), "[...] compõem hoje os textos da contemporaneidade". As seguintes transcrições, bem como as que já foram expostas, fazem ecoar as apreciações valorativas das booktubers a respeito das obras booktualizadas, por meio das unidades semióticas (verbais, gestuais, sonoras e visuais). Os fragmentos abaixo foram selecionados por apresentarem marcas linguístico-enunciativas que melhor explicitam as apreciações das booktubers. Vejamos:

Deni: /.../ Todos eles conseguiram mostrar (+) um GRANde nível de amizade:: $(+)$ o que é muito bonito e vai se fortificando cada vez mais ao longo da história (+) Eu gostei mui:to (+) o livro, também, tem várias imagens, o que complementa a história e dá (++) um um ar diferente (+) Eu amei esse livro |...

Isabela Lubrano: /.../ eu tô falando do fato de que a Alice se transformou numa referência cultural que é inerente à nossa infânci:a (+) /.../ Então (+) e-la compreende os absurdos que acontece no País das Maravilhas de uma maneira diferENte (+) e assim nos convida a ENxergar o nosso próprio MUN-do de uma outra forma $(+)$ E:: o que é melhor $(+)$ sem aquelas liçõezinhas $(+)$ CHA-tas, de moral que tem na maioria das histórias infantis $/ . . . /$ 
Mel Ferraz: /.../ O livro se transcorre em diversas aventuras (+) e:: (+) aventuras mUIto le::gais (+) / ... E:: apesar desse livro se: (=ser) fazer parte da literatura infantil $(+)$ eu tenho ele como algo assi::m, que:: TANto um adulto (+) quanto uma criança vão ser fisgados pela históri::a de uma maneira, de uma in-ten-si-dade:: iGUA:L /.../

Dentre as características multimodais selecionadas pelas booktubers na elaboração do gênero, destacamos algumas escolhas linguísticas, tais como: (i) os pronomes pessoais na primeira pessoa do singular e pronomes oblíquos na primeira pessoa do plural; (ii) os modificadores e marcadores apreciativos (adjetivos e orações adjetivas); (iii) os sintagmas verbais, seus modalizadores (advérbios); e os (iv) articuladores (preposição e conjunção). Esses recursos linguísticos foram empregados a serviço do conteúdo temático, e, por meio deles, é possível captar as marcas do sujeito enunciador - nesse caso, as booktubers.

Em relação à seleção dos elementos linguísticos, é importante ressaltar, a partir da transcrição acima, que nenhuma delas é neutra. No contexto de uso do gênero digital booktube, quando o sujeito diz "EU gostei" e/ou "EU amei" o pronome pessoal do caso reto, conjugado na $1^{\text {a }}$ pessoa do singular, demarca a responsividade ativa do sujeito enunciador em relação à sua própria avaliação sobre a obra booktualizada; ao passo que, quando a enunciadora seleciona o pronome oblíquo de $1^{\mathrm{a}}$ pessoa do plural - "NOS convida a enxergar o NOSSO mundo" - , ela apresenta a ideia de que a obra convida, não somente ela, mas todos os leitores, a enxergarem o mundo por um determinado ponto de vista. Além disso, a escolha do pronome possessivo de primeira pessoa do plural, "NosSo", demarca que a enunciadora assume a posição de alguém que compartilha um mundo em comum com os seus interlocutores. A percepção desses elementos no interior do enunciado concreto assevera a estreita relação entre o enunciado (gênero booktube) e sua função na interação socioverbal, a saber: apresentar, descrever e avaliar livros, além de debater e fazer indicações de suas leituras.

Assim, de forma geral, vimos que as apreciações valorativas realizadas pelas booktubers a respeito desses clássicos infantis são positivas, visto que todas elas fazem questão de mencionar que se trata de obras clássicas que devem ser lidas por todos, sejam adultos ou crianças. No entanto, é perceptível que duas dessas booktubers, Isabela Lubrano e Mel Ferraz, aprofundam suas avaliações sobre a obra lida a partir de 
V. 11 (3)

$386-412$

set-dez 2021 outros enunciados; elas extrapolam a simples descrição e indicação da obra quando optam por admitir outra construção composicional, que permite não apenas a sumarização e a avaliação, mas também a adição de informações extras, conforme mostramos no Quadro 2.

Outra vez, vale salientar que, concomitantes aos enunciados linguísticos sócio-histórico e ideologicamente proferidos pelas booktubers, a todo tempo, vimos a presença de elementos multimodais próprios das modalidades visual, sonora e gestual, demarcados pelos parênteses duplos $((.)$.$) - utilizados por nós para comentar algo que ocorre, ou seja, a descrição$ dos elementos multimodais utilizados na edição do gênero digital booktube.

Em relação à modalidade visual - que, segundo Rojo e Barbosa (2015, p. 108), é caracterizada por aspectos como "fotos, ilustrações, grafismos, vídeos, animações" - , as imagens abaixo demonstram que o plano de fundo do espaço, assim como a presença do livro booktualizado, demarcam o estilo do gênero. As estantes de livros e a matéria física do livro em mãos são elementos que reforçam a função social do gênero de levar "usuários de internet a utilizar a plataforma de vídeos [...] como canal de divulgação de opiniões e resenhas literárias" (CARPINTÉRO, 2019, p. 17). Observemos as imagens abaixo:

Figura 3 - Captura de tela do booktube produzido por Deni

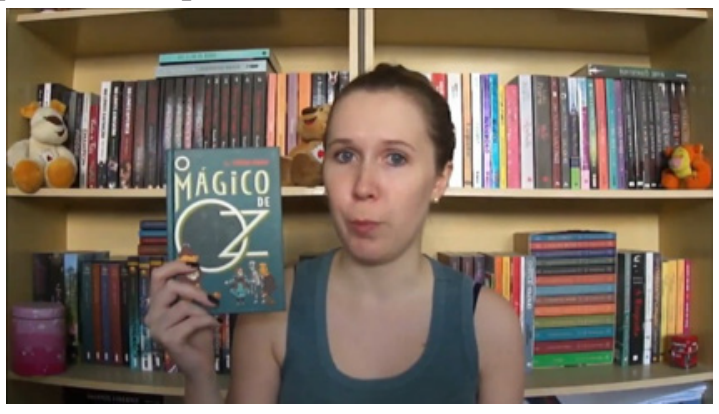

Fonte: YouTube (DENI, 2017).

Figura 4 - Captura de tela do booktube de Isabela Lubrano

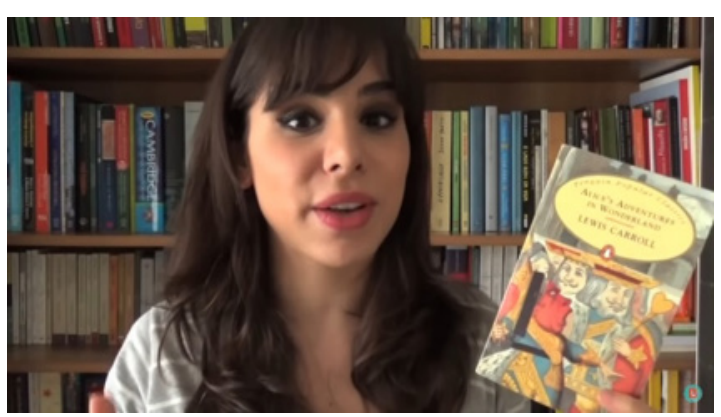

Fonte: YouTube (LUBRANO, 2015). 


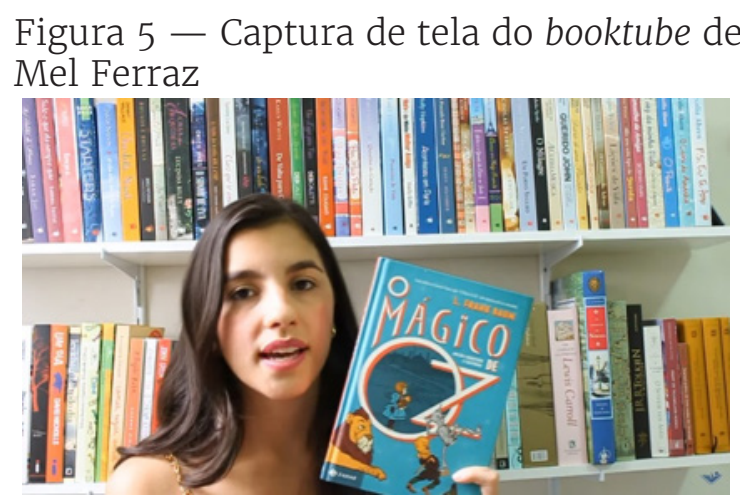

Fonte: Youtube (FERRAZ, 2014).

Por meio das figuras acima, vemos que o espaço físico utilizado para a elaboração do gênero booktube, em conjunto com a função social que ele exerce - com base nos booktubes analisados demarcam o estilo do gênero, pois são elementos comuns na produção dos três booktubes analisados. O estilo individual das booktubers, por sua vez, é caracterizado pela organização do espaço, pela orientação dos livros e objetos/enfeites dispostos, pelo tempo que sustentam os livros em mãos e até mesmo pelos elementos visuais utilizados na edição do vídeo, tais como as que são citadas na elaboração do Quadro 3. Assim, essas unidades temáticas estão associadas tanto ao estilo individual do autor quanto ao estilo do gênero (BAKHTIN, 2011), como mostramos nas figuras acima.

A partir dessas análises, admitimos o booktube como um gênero secundário do campo artístico, visto que ele ocorre em condições complexas de convívio cultural, o que pode ser comprovado tanto pelo ambiente no qual os vídeos são publicados quanto pelo fato de os booktubes se referirem a livros, objetos que fazem parte do campo supracitado. Isso posto, salientamos, que, de acordo com Bakhtin (2011, p. 305), "gêneros secundários da complexa comunicação cultural, em regra, representam formas diversas de comunicação discursiva primária". Apropriamo-nos desse pensamento para ressaltar que, embora apresente características dos gêneros primários, desenvolvidos em circunstâncias de comunicação verbal espontânea - a exemplo das narrativas espontâneas orais que ocorrem no ato enunciativo, simulando um diálogo face a face -, o booktube é um gênero secundário, desenvolvido em circunstâncias de comunicação verbal mais elaboradas, comuns às atividades científicas e artístico-literárias. 
V. 11 (3)

$386-412$

set-dez

2021

\section{Considerações finais}

Ao analisarmos o booktube com base em cada um dos elementos da tríade bakhtiniana - conteúdo temático, estrutura composicional e estilo - , confirmamos que ele é um gênero discursivo. Ou seja, o booktube é um enunciado relativamente estável, que circula na esfera científico-artística, com particularidades históricas, sociais e culturais, que variam em função das experiências do sujeito que o enuncia e do que se pretende significar.

A amostra delimitada neste estudo mostrou, em relação ao conteúdo temático, que, embora haja um campo comum na elaboração dos enunciados - visto que todos fazem parte do campo artístico-literário e enunciam apreciações valorativas a respeito de clássicos infantis esses enunciados não são rígidos, mas, ao contrário, flexíveis. O mesmo ocorre com a construção composicional e o estilo do gênero, visto que, na estrutura, constatamos variações que abarcam desde o tempo de gravação do vídeo até as diferentes ações de linguagem empregadas a serviço da funcionalidade do gênero: apresentar, descrever, avaliar livros e, também, debater suas leituras e fazer (ou não) recomendações sobre elas.

A análise dos elementos da tríade bakhtiniana foi realizada conforme ampliação sugerida por Rojo (2013) com relação às múltiplas linguagens mobilizadas para a formação do gênero do discurso booktube. No que diz respeito a tais linguagens, observamos, com base em Rojo e Barbosa (2015), as modalidades verbal, gestual, sonora e visual que compõem o booktube e confirmamos que o estilo desse gênero abarca não apenas unidades verbais, mas também não-verbais.

Nesse contexto, percebemos que, mesmo que haja semelhanças entre os dizeres e as escolhas multimodais de cada uma das booktubers, cada uma delas realiza o mesmo gênero de modo individual, isto é, de uma maneira única e irrepetível, sem que os atos realizados sejam tão diferentes, visto que, além de relativo, o gênero também é estável.

Assinalamos, ainda, que o booktube é um gênero discursivo secundário, mas que se mescla, durante sua ocorrência, com gêneros primários diversos - a exemplo de momentos nos quais a booktuber narra um acontecimento, conta uma piada ou faz um relato pessoal - e, ainda, com gêneros secundários como a resenha, com a qual compartilha a função e alguns elementos estruturais. 
Trata-se, portanto, de um gênero com grande potencial de enriquecimento da prática pedagógica no tocante às práticas de leitura e escrita de estudantes, visto que nele está incorporado o gênero secundário resenha, essencial para a formação de sujeitos críticos e criativos, aptos a protagonizarem criticamente as diversas práticas sociais instituídas pela oralidade, pela escrita e/ou por outras linguagens multimodais.

Cabe dizer, por fim, que a apropriação da noção de gênero do discurso de Bakhtin e seus desdobramentos têm sido muito enriquecedores para os estudos da Linguística Textual e da Educação. Ressaltamos, assim, a relevância de descortinarmos gêneros advindos das TDICs, como o booktube, para que o professor de língua portuguesa conheça seu funcionamento e saiba utilizá-lo em sala de aula. Dessa maneira, o docente faria valer ao menos duas das competências gerais a serem desenvolvidas na Educação Básica, instituídas pela Base Nacional Comum Curricular — BNCC - (BRASIL, 2018): 1) utilizar as diferentes linguagens multimodais e 2) compreender, utilizar e criar tecnologias digitais de forma crítica, significativa e ética.

\section{Referências}

ARAÚJO, Júlio César Rosa de. Transmutação de gêneros na web: a emergência do chat. In: XAVIER, Antonio Carlos; MARCUSCHI, Luiz Antônio (org.). Hipertexto e gêneros digitais: novas formas de construção de sentido. 3. ed. São Paulo: Cortez, 2010. p. 109-134.

BAKHTIN, Mikhail. Os gêneros do discurso. In: BAKHTIN, Mikhail. Estética da Criação Verbal. Introdução e tradução de Paulo Bezerra. 6. ed. São Paulo: WMF Martins Fontes, 2011.p. 261-306.

BRASIL. Base Nacional Comum Curricular: Versão final. Brasília: MEC/ Secretaria de Educação Básica, 2018.

CARPINTÉRO, Ana Carolina Barbosa. Caminhos da literatura na internet: o booktube e a partilha de experiências de leitura. 2019. 132f. Dissertação. (Mestrado em Literatura, Cultura e Contemporaneidade) - Pontifícia Universidade Católica do Rio de Janeiro, Rio de Janeiro, 2019.

DENI. VEDA \#7: Resenha O Mágico de Oz. 2017. (4min59s). Publicado no canal Leituras de Deni (online). Disponível em: https://www.youtube.com/ watch?v=SBWSZBPftJs. Acesso em: 10 dez. 2020.

DIONISIO, Angela. Gêneros textuais e multimodalidade. In: KARWOSKI, Acir Mário; GAYDECZKA, Beatriz; BRITO, Karim Siebeneicher (org.). Gêneros textuais: reflexões e ensino. São Paulo: Parábola Editorial, 2011. p. 137-152.

FARACO, Carlos Alberto. Linguagem \& diálogo: ideias linguísticas do círculo de Bakhtin. São Paulo: Parábola Editorial, 2009. 
V. 11 (3)

$386-412$

set-dez

2021
FERRAZ, Mel. [RESENHA] O Mágico de Oz. 2014. (18min39s). Publicado no canal Literature-se (online). Disponível em: https://www.youtube.com/ watch?v=qFEYgUqWNAk. Acesso em: 10 dez. 2020.

FIORIN, José Luiz. Introdução ao pensamento de Bakhtin. 2.ed. São Paulo: Contexto, 2016.

LUBRANO, Isabela. Alice No País Das Maravilhas, Lewis Carroll (\#18). 2015. (9min40s). Publicado no canal Ler Antes de Morrer (online). Disponível em: https://www.youtube.com/watch?v=K6kZ8E1EicM. Acesso em: 11 dez. 2020.

MACHADO, Anna Rachel. Revisitando o conceito de resumos. In: BEZERRA, Maria Auxiliadora; DIONISIO, Ângela Paiva; MACHADO, Anna Rachel (org.). Gêneros Textuais \& Ensino. São Paulo: Parábola Editorial, 2010. p. 149-162.

MACHADO, Irene. Gêneros discursivos. In: BRAIT, Beth (Org.). Bakhtin: conceitos-chave. São Paulo: Contexto, 2015. p. 151-166.

MARCUSCHI, Luiz Antônio. A. A transcrição de conversações. In: MARCUSCHI, Luiz Antônio. Análise da conversação, 5. ed. São Paulo: Editora Ática, 2003. p. 9-13.

MARCUSCHI, Luiz Antônio. Produção textual, análise de gêneros e compreensão. São Paulo: Parábola Editorial, 2008.

MOTTA-ROTH, Desirée; HENDGES, Graciela Rabuske. Produção textual na universidade. São Paulo: Parábola Editorial, 2010.

RIBEIRO, Pollyanne Bicalho. Funcionamento do gênero do discurso. Bakhtiniana, São Paulo, v. 1, n. 3, p. 54-67, $1^{\mathrm{O}}$ sem. 2010. Disponível em: https://revistas.pucsp.br/index.php/bakhtiniana/article/view/3370. Acesso em: 20 dez. 2020.

ROJO, Roxane. Gêneros discursivos do Círculo de Bakhtin e multiletramentos. In: ROJO, Roxane. (Org.). Escol@ Conectada: os multiletramentos e as TICs. São Paulo: Parábola, 2013.p. 13-36.

\section{ROJO, Roxane; BARBOSA, Jaqueline Peixoto. Hipermodernidade,} multiletramentos e gêneros discursivos. São Paulo: Parábola Editorial, 2015.

SILVA, Verônica Vitória de Oliveira. Booktube: a resenha literária como estratégia para o letramento literário. 2019. 152 f. Dissertação (Mestrado em Letras) - Universidade Federal de Minas Gerais, Belo Horizonte, 2019.

SOBRAL, Adail. Do dialogismo ao gênero: as bases do pensamento do círculo de Bakhtin. Campinas, SP: Mercado de Letras, 2009. 